\title{
Effect of Manufactured Sand on Flexural Behavior of Geopolymer RCC Beams: A review
}

\author{
T. Srinivas ${ }^{1}, P$. Bhavana $^{2}$, and N. V. Ramana $\mathrm{Rao}^{3}$ \\ ${ }^{1}$ Professor, Department of Civil Engineering, GRIET, Hyderabad-500090, India. \\ ${ }^{2}$ M.Tech Structural Engineering Student, GRIET, Hyderabad-500090, India. \\ ${ }^{3}$ Professor, Department of Civil Engineering, JNTUH, Hyderabad-500085, India.
}

\begin{abstract}
In recent days, the continuous running down of the ozone coat and global warming problem has greater than before, it is necessary to get the consciousness of the construction industries in using new recyclable construction materials. To suit this, geopolymer concrete has begun to boost massive concern from the research scholars and construction practitioners, because of its beneficial in utilizing byproduct materials to replace cement and diminishing ozone depleting substance release all through its generation. It is also having superior mechanical and durability properties compared to conventional concrete. On the other hand river sand is becoming scare day by day and costlier. So the manufactured sand turns out to be alternative material for river sand. In spite of its benefits, the use of geopolymer concrete in realistic is significantly narrow, this is primarily due to the deficiency in the studies in terms of structural elements, design and application. This paper objective is to identify the research gaps in this area and develop future research investigations in the materials and structural elements performance of geopolymer concrete. Many researchers from their analysis on flexural behavior of beams concluded that geopolymer concrete could replace conventional concrete.
\end{abstract}

${ }^{1}$ Corresponding Author Email: srinu.tummala@gmail.com 


\section{Introduction}

All around, concrete is as yet a main development material inferable from its wide-going mechanical properties, better long term performance, simple application, and cost-viability. "The concrete production which is assessed to be roughly one cubic meter per capita requires the assembling of concrete for a gigantic scope [1], The worldwide concrete interest is evaluated at over 4.216 billion metric tons in 2018 according to International Cement Review Research Report which further requires about $9.476 * 10^{7}$ Joules/ton of vitality utilization in its creation procedure" [1]. "It is evaluated that carbon dioxide discharged during concrete assembling process contributes around 5 to $7 \%$ of the absolute carbon dioxide discharged in nature which is considered as a conspicuous motivation to quicken an unnatural weather change".

The source material of GPC is wealthy in Aluminum (Al) and Silicon ( $\mathrm{Si}$, for example, fly debris (FA), metakaolin and GGBS [2]. "The source material responds with the activator which is a blend of sodium silicate $(\mathrm{Na} 2 \mathrm{SiO} 3)$ arrangement and sodium hydroxide $(\mathrm{NaOH})$ arrangement which delivers an inorganic polymeric fastener called geopolymer paste" [2]. Notwithstanding the natural reasons for utilizing GPC rather than OPC concrete, geopolymer binders showed better mechanical properties [3]. "Progressively finished, GPC has stength, quality, and other mechanical properties Fig 1 shows the flow pattern in the examination of geopolymer concrete. Evidently, the examinations done on geopolymer concrete before 2001 is impressively constrained, the quantity of studies expanded significantly from year 2016, showing the high consideration given by worldwide researchers in this specific field". In spite of huge and generous examinations being acted in such manner, geopolymer concrete still can't seem to get worldwide acknowledgment as development material. The causes can be summed up as follows: a)The cost of creation of geopolymer concrete requires to be sensibly serious. b)Extensive and increasingly dependable information are required on the common sense of utilizing geopolymer concrete as structural components.c)The setting up of structure of geopolymer components is perquisite.

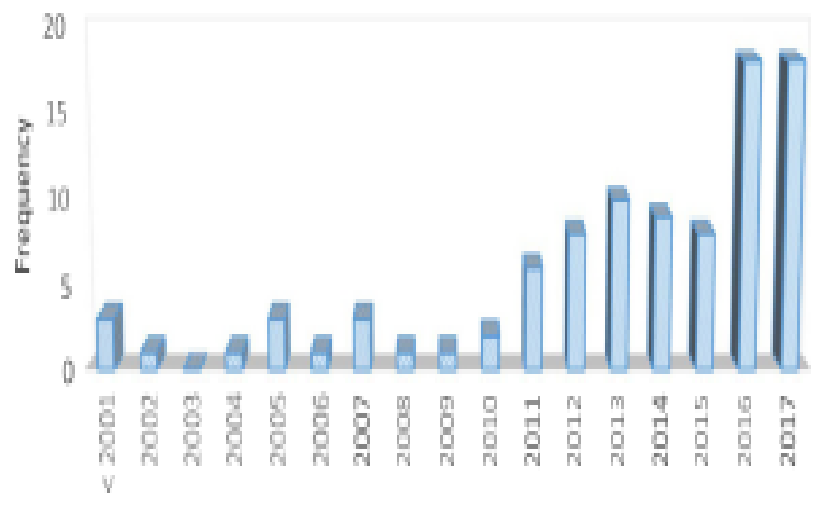

Fig.1. Research trend in geopolymer concrete
While a large portion of the examination takes microscale investigation on geopolymer concrete spotlight for smaller scope examination, ongoing analysts on the utilization of geopolymer concrete reaches out to the examination of the basic conduct of geopolymer concrete in load-bearing individuals, like beams, columns etc. "The auxiliary properties of the solid individuals like slabs is one of the most essential segment in successfully presenting such cement for real structures and applications, the congruity of the exhibition of fortified geopolymer concrete structures with existing plan arrangements ought to be found out so as to assess the attainability of utilizing these plan codes for geopolymer structures for the comfort of auxiliary structured engineers". Furthermore, "engineers would likewise have the option to deliver an increasingly reasonable, more secure and successful plan of geopolymer structures over the long run on information and discoveries from research works, for example, numerical models, experimental conditions, empirical conditions and wellbeing factors, among others, considering the significance of the auxiliary part of using geopolymer concrete in RCC structures, this survey sums up and talks about the distributed discoveries of exploration works including geopolymer concrete structures, for example, beams, columns, slabs and panels".

\section{SIGNIFICANCE OF THE STUDY}

"Geopolymer materials are discovering its way towards replacing traditional development materials as green materials, yet at the same time, the exploration is restricted to heat curing conditions. The extent of adequacy of geopolymer products, for example, geopolymer mortar, paste and concrete can be extended on the off chance that they can appropriately and monetarily be created at ambient temperature curing conditions". This examination explored the ongoing improvement in geopolymer items with the consideration of different mineral admixtures and mechanical properties of various structural components.

\section{PREVIOUS STUDIES ON GEOPOLYMER CONCRETE}

\subsection{Research in materials}

Broad investigations have been performed to survey the exhibitions of geopolymer concrete. They explained the impacts of C-S-H stage, admixtures and curing processes. yip et al[4] announced that in MK/SG-based geopolymer pastes, C-S-H and aluminosilicate gel $(\mathrm{N}-$ A-S-H) can be found. This is very like a high calcium FA-based geopolymer, initiated especially by sodium hydroxide $(\mathrm{NaOH})$, as revealed by Somna et al.[5]. The quality of concrete is come up with the C-S-H and N-A$\mathrm{S}-\mathrm{H}$. At the end of the day, the quality of geopolymer paste is exceptionally reliant on the alkalinity rank of activators utilized. Additionally, it was likewise 
announced that the temperature assumes significant job in initiating the aluminosilicates. "Exploration found that in FA/SG mixes, the actuation procedure at lower temperature (at roughly $27^{\circ} \mathrm{C}$ ) is commanded by $\mathrm{SG}$ enactment, though at higher temperature level (at around $60^{\circ} \mathrm{C}$ ), both FA and SG is actuated, all things considered, the SG is contributing in the quality of paste because of its smallness of microstructure"[6]. "The hardening of FA/SG-based geopolymer is because of C$\mathrm{S}-\mathrm{H}$ and C-A-S-H" formation. "The solidifying is trailed by the arrangement of C-S-H, N-A-S-H and C-A-S-H, nonetheless, the arrangement of hydrate gels is subject to the calcium particles and $\mathrm{pH}$ levels". Prinya et al.[7]revealed that acidic condition delivering N-A-S-H gel in FA-based geopolymers. High convergence of calcium particle in class C FA-based geopolymers can bring about high compressive strength [8]. "The availability of high potassium oxide content in HCWA added to the early strength development of events [9] and added to the self-actuation of geopolymer without the utilization of alkaline activator" [10] .

As a rule, the writing audits have obviously demonstrated that geopolymer cement can be grouped by fly ash based, metakaolin-based, slag-based and blend of both of these aluminates assets as introduced in Fig. 2. What's more, the connections every boundary with the geopolymer concrete are showed. Likewise, Fig. 2 features on techniques or approaches utilized for exhibitions appraisal of geopolymer concrete with the impacts of different factors.

The results of the previous studies with dissimilar activators, parameters and procedures to evaluate the performance have been listed. "The content aggregation frequency of subject areas with regards to different authors, the activators utilized, and the methods or approaches adopted to assess the performance of geopolymer concrete, in previous papers, forty-two (45) studies have been performed on FA-based, seven (7) on MK-based, six (6) on SG- based, two (2) on RHAbased and HCWA-based whilst nineteen(19) focused on combined aluminosilicates resources". This also revealed that "sixty-four (64) authors used $\mathrm{NaOH}$, seven (7) authors used $\mathrm{KOH}$, fifty-five (55) authors used $\mathrm{Na}_{2} \mathrm{SiO}_{3}$ and four (4) authors used $\mathrm{K}_{2} \mathrm{SiO}_{3}$, it can also be seen that two (2) authors did not used any activators to assess the capability of HCWA in activating the geopolymer".

"The methods used to evaluation the reactivity of activators includes sorptivity test, compression test, SEM, EDS, XRD, slump test, water intrusion test, $\mathrm{pH}$ test, UPV and rebound hammer test for geopolymer concrete material, whilst in structurally, column, beam and slab tests were performed, it shows cylinder compression test is to be often adopted as assessment". It came to know that forty-seven (47) authors used this test. "In addition to compression test, seventeen (17) used sorptivity test, six (6) used water intrusion test, nine (9) used UPV, eight (8) used pH tests, twenty-one (21) used SEM/EDS, thirteen (13) used XRD, fourteen (14) used slump tests, three (3) used rebound hammer test and one (1) used impact test, meanwhile, eleven (11) authors used beam test, six (6) authors used column test and two (2) used slab tests". It should be noted that "different tests were performed to identify efficiency of each group of activators in affecting the mechanical properties, fresh properties, durability and structural performances of geopolymer concrete.

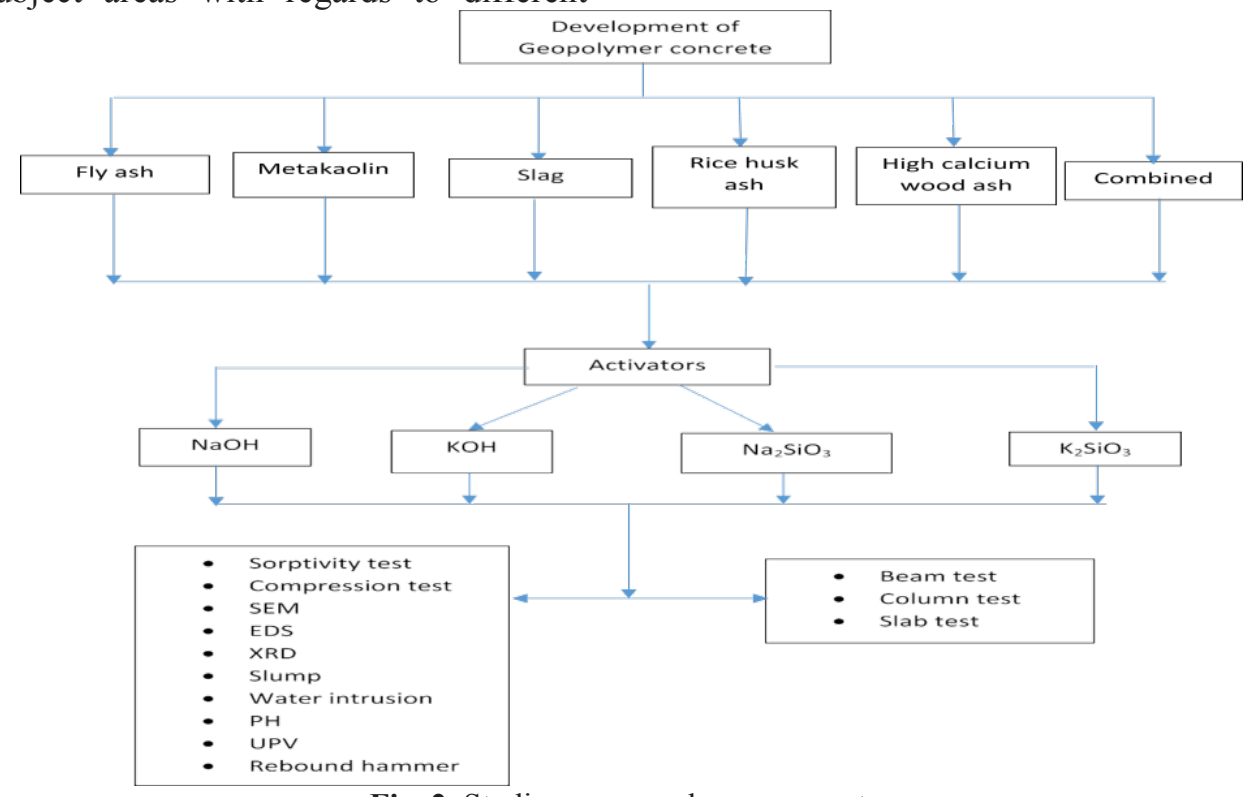

Fig. 2. Studies on geopolymer concrete.

\subsection{Research in structural elements}

The examination of geopolymer concrete has been stretched out to structural elements such as beams, columns and slabs. "It was found that the structural behaviour of FA-based geopolymer concrete beam similar to the ordinary reinforced concrete beams" [11]. To expand the exhibition of geopolymer solid bar, the impacts of extra steel fiber were explored by $\mathrm{Ng}$ et 
al.[12]. "It was found that the shear capacity of beam was delayed due to additional fiber, finer crack was also observed, it was reported that lower post-peak ductility was observed when $\mathrm{SG}$ is added to FA-based geopolymer concrete" [13]. "As in FA- based geopolymer concrete column, trivial difference in failure mode was observed compared to conventional column" [14]. "Brittle failure was reported for geopolymer concrete columns[11], to increase the load carrying

\section{DISCUSSION AND SUGGESTION}

The variables that influence the mechanical conduct of geopolymer concrete are different. Along these lines, a ton of endeavors are required to comprehend the mechanical conduct of this material. Table 1 shows that numerous boundaries inspected were for fly ash based GPC. "The majority of the past investigates have thought about the proportion among aluminosilicates and activators, mix and influence of the extra fibres in their examinations as factors, it additionally required more examination between the mechanical behaviour of reinforced GPC structural elements and OPC structural elements for having an away from of the conduct of both cement". Substitution of River sand by M-sand would be progressively pragmatic for better outcomes

For well-understand, "the behaviour of reinforced GPC structural elements, the development models for predicting the flexural strength of reinforced GPC beams and load-carry capacity of reinforced GPC columns are essential and compare the predicted values of models with the experimental values".

\section{CONCLUSIONS}

The accompanying focuses sum up the eminent properties of reinforced geopolymer concrete and its effectiveness as a functional development item for what's to come in future:

- Various significant attributes of geopolymer materials including decreased contamination, high-performance durability in an aggressive environment, cost-viability, and eco-amicability make them planned supportable materials in the development business .

- $\quad$ Since, GPC is making use of an industrial byproduct $(\mathrm{FA})$, it is relatively economical to manufacture, further, the manufacture of GPC does not create detrimental green- house gas emissions.

- Investigational results showed that the mechanical properties in terms of compressive and bending strengths of GPC are as good as the OPC. Though, the GPC specimens show signs of no considerable strength loss for the duration of acute thermal loads.

- GPC doesn't require long curing periods normally important for OPC-based materials. capacity and the ductility of geopolymer concrete column, steel fibers and confinement can be used[16,17], while in geopolymer concrete slabs, it was found that the ductility and energy absorption are better compared to ferrocement slabs" $[18,19]$. "Below information shows the summary of past literatures on geopolymer concrete elements. Detail of the structural performances of geopolymer reinforced concrete has been reported by Mo et al".[19].

The early response degree and resulting reinforcing are speedy in alkali-activated system, and the times of curing somewhere in the range of three and $8 \mathrm{~h}$ can create hardened cement with promising strength capabilities.

- Taken as a whole, FA-based geopolymer concrete tends to minor dry shrinkage for the period of the curing. Dimensional stability in terms of durability is a major issue. Conventional concrete tends to present considerable volume decrease as an outcome of water losses during the reaction. GPC maintain a lot of moisture during the reaction, and the result is a minor loss of mass

\section{REFERENCES}

1. P.K. Mehta," Development, High-performance, high-volume fly ash concrete: materials, mixture proportioning, properties, construction practice, and case histories, Suppementary Cementing Materials for Sustainable Development, (2002) .ISBN 097315070X

2. A. Hassan, M. Arif, and M. Shariq, "A review of properties and behaviour of reinforced geopolymer concrete structural elements- A clean technology option for sustainable development," J. Clean. Prod., vol. 245, p. 118762, (2020).

3. N. A. Farhan, M. N. Sheikh, and M. N. S. Hadi, "Investigation of engineering properties of normal and high strength fly ash based geopolymer and alkali-activated slag concrete compared to ordinary Portland cement concrete," Constr. Build. Mater., vol. 196, pp. 26-42, (2019)

4. C. K. Yip, G. C. Lukey, and J. S. J. van Deventer, "The coexistence of geopolymeric gel and calcium silicate hydrate at the early stage of alkaline activation," Cem. Concr. Res., vol. 35, no. 9, pp. 1688-1697, (2010).

5. K. Somna, C. Jaturapitakkul, P. Kajitvichyanukul, and $\mathrm{P}$. Chindaprasirt, " $\mathrm{NaOH}$-activated ground fly ash geopolymer cured at ambient temperature," Fuel, vol. 90, no. 6, pp. 2118-2124, (2011).

6. S. Kumar, R. Kumar, and S. P. Mehrotra, "Influence of granulated blast furnace slag on the reaction, structure and properties of fly ash based geopolymer," J. Mater. Sci., vol. 45, no. 3, Art. no. 3 , (2010).

7. P. Chindaprasirt, C. Jaturapitakkul, and T. Sinsiri, "Effect of fly ash fineness on compressive strength 
and pore size of blended cement paste," Cem. Concr. Compos., vol. 27, no. 4, pp. 425-428, (2005).

8. Tummala Suresh Kumar, Kosaraju Satyanarayana, Materials Today: Proceeding, 26 (2), 3228-3233, (2020).

9. C. C. Ban, M. H. Samsudin, and M. Ramli, "Optimization on the Alkaline Activator Content of Hybridize Ground Granulated Blast Furnace Slag and High Calcium Wood Ash (GGBS-HCWA) for the Fabrication of Geopolymer Mortar," $A d v$. Sci. Lett., vol. 24, no. 6, pp. 4193-4195, (2018).

10. C. C. Ban, P. W. Ken, and M. Ramli, "Mechanical and Durability Performance of Novel Selfactivating Geopolymer Mortars," Procedia Eng., vol. 171, pp. 564-571, (2017).

11. T. S. Ng, A. Amin, and S. J. Foster, "The behaviour of steel-fibre-reinforced geopolymer concrete beams in shear," Mag. Concr. Res., vol. 65, no. 5, pp. 308-318, Mar. 2013,

12. M. Rahman and P. Sarker, "Geopolymer Concrete Columns under Combined Axial Load and Biaxial Bending," presented at the CONCRETE 2011 Conference, 2011.

13. N. Ganesan, R. Abraham, S. Deepa Raj, and K. Namitha, "Effect of fibres on the strength and behaviour of GPC columns," Mag. Concr. Res., vol. 68, no. 2, pp. 99-106, (2015).

14. M. Rajendran and N. Soundarapandian, "An experimental investigation on the flexural behavior of geopolymer ferrocement slabs," J. Eng. Technol., vol. 3, no. 2, p. 97, (2013).

15. S. Nagan and R. Mohana, "behaviour of geopolymer ferrocement slabs subjected to impact," vol. 38, p. 11, (2014).

16. Rajagiri A, MN Sandhya, Nawaz S, Suresh Kumar T, E3S Web of Conferences 8701004 (2019)

17. J. R. Yost, A. Radlińska, S. Ernst, and M. Salera, "Structural behavior of alkali activated fly ash concrete. Part .Mixture design, material properties and sample fabrication," Mater. Struct. Constr., vol. 46, no. 3, pp. 435-447, (2013).

18. R. Andalib, M. W. Hussin, M. Z. A. Majid, M. Azrin, and H. H. Ismail, "Structural Performance of Sustainable Waste Palm Oil Fuel Ash-Fly Ash Geo-polymer Concrete Beams," vol. 2, no. 3, p. 6, (2014).

19. P. Kathirvel and S. R. M. Kaliyaperumal, "Influence of recycled concrete aggregates on the flexural properties of reinforced alkali activated slag concrete," Constr. Build. Mater., vol. P1, no. 102, pp. 51-58, (2016).

20. M. Albitar, M. Ali, P. Visintin, and M. Drechsler, "Effect of granulated lead smelter slag on strength of fly ash-based geopolymer concrete," Constr. Build. Material., vol. 83, (2015).

21. T Srinivas and N V Ramana Rao, " A Study on Flexural Behavour of RCC beams containing High Volume Fly Ash", (IOSR-JMCE), Volume 12, Issue 4 Ver. II, PP 01-06,.(2015),
22. Srinivasa Reddy, V., Seshagiri Rao, M.V., Shrihari, $\mathrm{S}$, "Appraisal of processing techniques for recycled aggregates in concrete", IJEAT, 8 (6), pp. 16611665, (2019).

23. Sateesh, N., Sampath Rao, P., Ravishanker, D.V., Satyanarayana, K., "Effect of Moisture on GFRP Composite Materials", Materials Today: Proceedings, 2 (4-5), pp. 2902-2908, (2015).

24. Satyanarayana, G.V.V., Saikiran, C.H, "Effect on mechanical properties of M35 grade concrete by partial replacement of fine aggregate with copper slag", IJITEE, 8 (12), pp 3759-3762, (2019).

25. Mallikarjuna Reddy, V., Praveen, R., " Effect of polyethylene glycol in self-curing of self compacting concrete", IJRTE, 8 (3), pp. 72807283, (2019) 
21. 